\section{What is already known on this topic}

Health promotion payments have been made to UK general practitioners since 1990, but their effectiveness is unknown

\section{What this study adds}

Primary care staff held strong negative views about the pilot payments to promote smoking cessation and previous health promotion payments

The highest claiming practitioners altered their methods of recording smoking status rather than increasing the frequency with which they advised patients against smoking

Future changes in health promotion payments should be carefully piloted

are made available, general practices seem to follow the path of least resistance to claim them. This often involves simple administrative changes rather than changes in clinical behaviour. New payments for health promotion should be carefully piloted and evaluated to determine whether they alter clinical practice.

We thank Margaret Whatley and Pauline Green for secretarial help, Toby Gosden for comments on an earlier version of this report, the 13 general practices that participated in the study, and Orest Mulka, who proposed the new health promotion payment. Funding: Trent NHS Executive and Medisearch.

Competing interests: None declared.

1 Lowy A, Brazier J, Fall M, Thomas K, Jones N, Williams D, et al. Mino surgery by general practitioners under the 1990 contract: effects on hospital workload. BMJ 1993;307:413-7.

2 Ritchie LD, Bisset AF, Russell D, Leslie V, Thomson I. Primary and preschool immunisation in Grampian: progress and the 1990 contract. BMJ 1992;304:816-9.

3 Hughes D, Yule B. The effect of per-item fees on the behaviour of general practitioners. J Health Econ 1992;11:413-37.

4 Hughes D. General practitioners and the new contract: promoting better health through financial incentives. Health Policy 1993;25:39-50.
5 Gosden T, Forland F, Kristiansen IS, Sutton M, Pedersen L, Leese B, et al. Capitation, salaried, fee for service and mixed systems of payment and the behaviour of primary care physicians. In: Bero L, Grilli R, Grimshaw J, Oxman A, eds. Collaboration on effective practice module of the Cochrane Database of Systematic Reviews. Cochrane Library. Issue 1. Oxford: Cochrane Collaboration. Update Software, 1998:CD002215.

6 Giuffrida A, Gosden T, Forland F, Sergison M, Leese B, Pedersen L, et al Target payments in primary care: effects on practice and health outcomes. In: Bero L, Grilli R, Grimshaw J, Oxman A, eds. Collaboration on effective practice module of the Cochrane Database of Systematic Reviews. Cochrane Library. Issue 1. Oxford: Cochrane Collaboration. Update Software, 1998:CD000531.

7 Reid GS, Robertson AJ, Bissett C, Smith J, Waugh N, Halkerston R. Cervical screening in Perth and Kinross since introduction of the new contract. BMI 1991;303:447-50.

8 Department of Health. General practice in the National Health Service: a new contract. London: HMSO, 1989

9 LeTouze S, Calnan M. Evaluation of the new health promotion package for general practice. Canterbury: Centre for Health Service Studies, University of Kent, 1995.

10 Dowell AC, Ocheran JJ, Hilton SR, Bland JM, Harris T, Jones DR, et al. Prevention in practice: results of a 2-year follow-up of routine health promotion interventions in general practice. Fam Pract 1996;13:357-62.

11 Coleman T, Wilson A. Anti-smoking advice in general practice consultations: general practitioners' attitudes, reported practice and perceived problems. Br J Gen Pract 1996;46:87-91.

12 Coleman T, Murphy E, Cheater FC. Factors influencing discussions about smoking between general practitioners and patients who smoke: a qualitative study. BrJ Gen Pract 2000;50:207-10.

13 Williams A, Boulton M. Thinking prevention: concepts and constructs in general practice. In: Lock M, Gordon D, eds. Biomedicine examined. London: Reidel, 1988

14 Tapper-Jones L, Smail SA, Pill R, Davis RH. Doctors' attitudes towards patient education in the primary care consultation. Health Educ J 1990;49:47-50

15 Coleman T, Wynn AT, Barrett S, Wilson A, Adams S Intervention study to evaluate pilot health promotion payment aimed at increasing general practitioners' antismoking advice to smokers. BMJ 2001;323:435-6.

16 Britten N. Qualitative interviews in medical research. BMJ 1995;311:251-3.

17 Fitzpatrick R, Boulton M. Qualitative research in health care. 1. The scope and validity of methods. J Eval Clin Pract 1996;2:123-30.

18 Strauss A, Corbin J. Basics of qualitative research: grounded theory procedure and techniques. Newbury Park, CA: SAGE, 1998.

19 Coleman T, Wynn A, Barrett S, Wilson A, Adams S. Prospective evaluation of a pilot health promotion payment aimed at increasing GPs' anti smoking advice to smokers: a report to Trent NHSE. Leicester: University of Leicester, 2000.

20 Bates C, McNeil A, Owen L. Smoking cessation services: implementing the national plan. London: Action on Smoking and Health, 2000.

21 Dey P, Foy R, Woodman M, Fullard B, Gibbs A. Should smoking cessation cost a packet? A pilot randomised controlled trial of the cost-effectiveness of distributing nicotine replacement therapy free of charge. $\mathrm{Br} \mathrm{J} \mathrm{Gen} \mathrm{Pract}$ $1999 ; 49: 127-8$

(Accepted 21 May 2001)

\title{
Intervention study to evaluate pilot health promotion payment aimed at increasing general practitioners' antismoking advice to smokers
}

\author{
Tim Coleman, Alison T Wynn, Steve Barrett, Andrew Wilson, Susan Adams
}

Since 1990, the UK government has tried to influence health promotion activity by general practitioners through payment schemes. ${ }^{1}$ These have never been rigorously evaluated. ${ }^{2}$ We examined the feasibility and effectiveness of a payment scheme that aimed to increase general practitioners' antismoking advice in an uncontrolled before and after study.

\section{Participants, methods, and results}

The health promotion payment was piloted in a deprived area of Leicester. The recruitment of practices is described elsewhere. ${ }^{3}$ Thirty five general practitioners (out of 62 approached) from 13 general practices (out of 28 approached) were recruited, and 31 participated in the study.

Before data collection began, we invited all members of primary healthcare teams to attend training in methods of stopping smoking. We then observed normal clinical behaviour over nine months (the control period). In the following nine months (the intervention period), practices could claim $£ 15$ from the health authority for identifying each patient who had smoked during the past year but was currently not smoking and had not done so for at least three months. We estimated that individual general practitioners could claim between $£ 285$ and $£ 1125$ annually.
See $\mathrm{p} 432$ Department of General Practice and Primary Health Care, Leicester Warwick Medical School, Leicester General Hospital, Leicester LE5 4PW Tim Coleman senior lecturer

Alison T Wynn research associate Andrew Wilson senior lecturer

continued over BMJ 2001;323:435-6 
Children's Brain Tumour and Disability Research

Centre, Academic

Division of Child

Health, School of

Human

Development,

University of

Nottingham,

Nottingham

NG7 2UH

Steve Barrett

research coordinator

Division of

Cardiology,

Department of

Medicine,

University of

Leicester, Leiceste

LE3 9QP

Susan Adams

research associate

Correspondence to:

T Coleman

tjc3@le.ac.uk
Comparison of patients in control and intervention periods. Values are numbers (percentages) of patients unless stated otherwise

\begin{tabular}{|c|c|c|c|}
\hline Characteristic (No answering question) & Control period & Intervention period & $P$ value for difference \\
\hline Completed first questionnaire & $1601 / 1878^{*}(85.3)$ & $1354 / 1647 \dagger(82.2)$ & 一 \\
\hline Women & $1064 / 1601(66.5)$ & $860 / 1354(65.5)$ & 0.09 \\
\hline Mean age (years) $(n=2928)$ & 44.0 & 45.3 & $<0.05 \ddagger$ \\
\hline Regular smokers $(n=1026)$ & $527 / 1601(32.9)$ & 499/1334 (36.9) & $0.03 \S$ \\
\hline Had tried stopping in past year $(n=1013)$ & $205 / 518(39.6)$ & $218 / 495(44.0)$ & $0.15 \S$ \\
\hline Intended to quit in next month $(\mathrm{n}=1007)$ & $97 / 515(18.8)$ & $137 / 492(27.8)$ & $0.001 \S$ \\
\hline Confident of being able to stop $(n=1010)$ & $138 / 517(26.7)$ & $156 / 493(31.6)$ & $0.08 \S$ \\
\hline Want to stop $(n=1004)$ & $268 / 513(52.2)$ & $297 / 491(60.5)$ & $0.008 \S$ \\
\hline Thinking about or trying to stop $(n=1004)$ & $209 / 513(40.7)$ & $218 / 491(44.4)$ & $0.24 \S$ \\
\hline $\begin{array}{l}\text { Seeing general practitioner about themselves and perceive they have a smoking } \\
\text { related problem }(n=806)\end{array}$ & 75/396 (18.9) & $80 / 410(19.5)$ & $0.84 \S$ \\
\hline Completed second questionnaire & $466 / 527(88)$ & 461/499 (92) & $0.03 \S$ \\
\hline Recalled antismoking advice & $100(21)$ & $87(19)$ & $0.62 \eta$ \\
\hline
\end{tabular}

*6 patients excluded, 226 missed, and 45 refused to participate.

t10 patients excluded, 231 missed, and 52 refused to participate.

¥By $t$ test.

$\S$ By $\chi^{2}$ test.

IP value for median difference in percentages by Mann-Whitney U test.

We needed to recruit 904 smokers to measure a $10 \%$ absolute change in the proportion of smokers receiving antismoking advice from their general practitioner, with $80 \%$ power at a $5 \%$ significance level. A research assistant asked all patients (parents or guardians of those $<16$ years) attending a random selection of general practitioners' surgeries to complete a questionnaire before the consultation. This sought sociodemographic details, identified regular smokers (those smoking on, at least, most days), and asked about smoking behaviour and smoking related problems. Smokers were asked to complete a second questionnaire after the consultation, asking whether they had been given antismoking advice. Patients who could not complete the questionnaires were excluded. We compared the researcher's records with those of receptionists to estimate the number of missed patients.

We compared the proportions of regular smokers who recalled discussion of smoking with their general practitioners before and after introduction of payments using the Mann-Whitney $\mathrm{U}$ test and allowing for clustering of data.

The table shows that patients in the intervention group were older and more motivated to stop smoking than those in the control group but that the distribution of smoking related problems was similar in both groups. We found no significant difference in the proportion of smokers recalling general practitioners' antismoking advice before and after introduction of the payment.

The numbers of smokers seen by each general practitioner (cluster size) varied greatly, and the proportions of smokers recalling antismoking advice were not normally distributed (intercluster correlation coefficient for recall of antismoking advice $=0.052$ ). Fourteen doctors made no claims, 15 made one to nine claims, and four made over 10 .

\section{Comment}

Paying general practitioners to identify smokers who had stopped smoking for three months or more did not make them give antismoking advice more frequently. The reasons behind the failure of the payments to change behaviour are explored elsewhere. ${ }^{3}$
Our findings could have been influenced by external factors, and offering smoking cessation training before the study started may have increased the amount of advice given during the control period. ${ }^{4}$ This would make it difficult to detect a small effect of the payment. Differences between the control and intervention groups at baseline are unlikely to account for our findings. ${ }^{5}$ We have no evidence to argue for a cluster randomised control trial of this payment scheme.

We have shown that it is feasible to investigate the introduction of a general practice health promotion payment in a prospective, experimental study. Future payment schemes can and should be evaluated using experimental methods.

We thank Margaret Whatley for secretarial help and Keith Stevenson and Toby Gosden for commenting on earlier versions of this paper. We also thank Tina Booth and Jane Roberts, who provided health promotion training, and Leicestershire Health, especially Iain Harkess and Clifford Hughes, who practices that participated in the study and Orest Mulka, who had the original idea for the health promotion payment.

Contributors: TC and AW obtained funding for the study. ATW and SB collected data and SA advised on statistical analysis. TC wrote the paper and all other authors commented on drafts. TC is the guarantor.

Funding: Trent NHS Executive and Medisearch.

Competing interests: None declared.

1 Department of Health. General practice in the national health service: a new contract. London: HMSO, 1989.

2 Giuffrida A, Gosden T, Forland F, Sergison M, Leese B, Pedersen L, et al. Target payments in primary care: effects on practice and health outcomes. In: Bero L, Grilli R, Grimshaw J, Oxman A, eds. Collaboration on effective professional practice module of the Cochrane Database of Systematic Reviews. Cochrane Library. Oxford: Update Software, 2000. CD000531.

3 Coleman T, Wynn AT, Stevenson K, Cheater F. Qualitative study of pilot payment aimed at increasing general practitioners' antismoking advice to smokers BMJ 2001;323:432-5.

4 Lancaster T, Silagy C, Fowler G. Training health professionals in smoking cessation. Cochrane Database Syst Rev 2000;(2):CD000214.

5 Coleman T, Wilson A. Factors associated with provision of anti-smoking advice by general practitioners. Br J Gen Pract 1999;49:557-8. (Accepted 21 May 2001)

\section{Endpiece}

\section{The editing urge}

The strongest drive is not love or hate. It is one person's need to change another's copy. helped complete the main study. Finally, we wish to thank the 13 